\title{
Editorial \\ Is there more to Wnt signalling in breast cancer than stabilisation of $\beta$-catenin?
}

\author{
Giovanna M Collu, Olivier Meurette and Keith Brennan
}

Faculty of Life Sciences, University of Manchester, Oxford Road, Manchester, M13 9PT, UK

Corresponding author: Keith Brennan, Keith.Brennan@manchester.ac.uk

Published: 30 July 2009

Breast Cancer Research 2009, 11:105 (doi:10.1186/bcr2336)

This article is online at http://breast-cancer-research.com/content/11/4/105

(c) 2009 BioMed Central Ltd

See related research by Matsuda et al., http://breast-cancer-research.com/content/11/3/R32

\begin{abstract}
Increased Wnt signalling has been implicated in the aetiology of many different human cancers, including breast cancers. In most cases, Wnt signalling is thought to drive tumourigenesis through the stabilisation of cytosolic $\beta$-catenin and the subsequent changes in the expression of T-cell factor (TCF)-dependent genes. However, this is not necessarily the only mechanism, as Wnt proteins can signal through a number of different intracellular signalling pathways. The ongoing work from Nancy Hynes' laboratory continues to highlight this latter possibility.
\end{abstract}

In their most recent article in Breast Cancer Research, Matsuda and colleagues [1] showed that expression of the secreted Wnt antagonist secreted Frizzled-related protein (sFRP) 1 reduced the ability of the breast cancer cell line MDA-MB-231 to form tumours in an orthotopic xenograft model. Using micro-array analysis, they demonstrated that sFRP1 downregulated Cyclin D1 expression, whilst CDKN1A, which encodes the cell cycle regulator $\mathrm{p} 21$, was upregulated, leading to an inhibition of proliferation. In addition, they indicate that $\beta 1$-integrin and the extracellular matrix proteins fibronectin and laminin are downregulated, which will also reduce proliferation as attachment to the extracellular matrix is required to maintain the proliferative potential of epithelial cells. Furthermore, they showed Wnt signalling promoted cell migration and that sFRP1 inhibited Wnt1-induced motility in a scratch-assay. In vivo, this antimigratory effect may contribute to the reduced ability of sFRP1-expressing MDA-MB-231 cells to form lung metastases when injected into the host bloodstream.

This recent paper builds upon previous work from the Hynes group addressing the role of Wnt signalling in breast cancer. They have shown that Wnt signalling in the HC11 immortalised mammary epithelial cell line induced an ErbB1/
Epidermal growth factor receptor (EGFR)-dependent activation of extracellular signal-regulated kinase (ERK) signalling [2]. Consistently with this, the inhibition of autocrine Wnt signalling in a panel of breast cancer cell lines led to a reduction in ERK activity and a corresponding inhibition of proliferation [3]. Interestingly, their work has suggested that the activation of ErbB1/EGFR signalling was through a $\beta$-catenin-independent mechanism.

Wnt1 was the first oncogene to be described in the mammary gland [4] and its potency was reiterated by the ability of Wnt1 to transform primary human mammary epithelial cells alone, unlike the classical oncogenes encoding Ras and SV40 large T antigen, which must act in combination [5]. The aberrant activation of Wnt signalling in many cancers, especially colorectal cancer, can be attributed to elevated levels of cytosolic and nuclear $\beta$-catenin leading to changes in the expression of TCF-dependent genes. This occurs through mutations in components of the $\beta$-catenin destruction complex or mutations in $\beta$-catenin itself that prevent it from being targeted for proteosomal degradation [6]. However, in breast cancer, such mutations are rare, despite the clear nuclear accumulation of $\beta$-catenin in breast cancer cells [7]. Instead, Wnt activation seems to occur at the level of the Wnt ligand-receptor interaction, through the upregulation of ligands and receptors and the downregulation of secreted inhibitors $[3,8,9]$. This raises the possibility that other Wnt pathways, in addition to $\beta$-catenin signalling, are active in breast cancer.

Several distinct events can occur following Wnt-Frizzled receptor binding, in addition to $\beta$-catenin stabilisation. Although not fully characterised, these have been loosely grouped into the 'non-canonical' pathways, which include the

EGFR $=$ epidermal growth factor receptor; ERK $=$ extracellular signal-regulated kinase; LRP $=$ Low density lipoprotein receptor-related protein; $\mathrm{PCP}=$ Planar cell polarity; PKC = protein kinase $\mathrm{C} ; \mathrm{sFRP}=$ secreted frizzled-related protein; TCF $=$ T-cell factor. 
Wnt/Planar cell polarity (PCP) and the Wnt/protein kinase C (PKC) pathways [10]. In their most recent paper, Matsuda and colleagues make the link between Wnt signalling and regulation of cell motility [1]. Many studies have shown a link between Wnts and cell motility mediated by PCP signalling [10]. This pathway requires Frizzled, but not Low density lipoprotein receptor-related protein (LRP)5/6, and links ligand-binding to the Rho family of small GTPases. Indeed, Matsuda and colleagues suggest that the migratory effect of Wnts can be blocked using a Rho kinase inhibitor [1]. Furthermore, Wnt/PKC signalling, which is also dependent upon Frizzled and Dishevelled but not $\beta$-catenin, is clearly linked to the metastatic potential of invasive melanoma [11], although a role for this pathway in breast cancer has not yet been reported. In light of this, it is very interesting that the phenotypes of mammary tumours that arise from overexpressing either Wnt proteins or stabilised forms of $\beta$-catenin are different [12]. Although this difference could be due to the secreted Wnt proteins signalling to neighbouring tissues in a paracrine fashion, it could also represent the effects of simultaneous activation of both $\beta$-catenindependent and -independent pathways.

Given the ability of Wnt signalling to directly affect cellular processes such as proliferation, differentiation and migration, as well as its ability to activate signalling through other oncogenic pathways such as ErbB1/EGFR [2,3], Notch $[5,13]$ and Hedgehog [12], it is no surprise then that therapeutically targeting Wnt activity is so attractive. A recent publication has identified several small molecule inhibitors of Wnt signalling [14], one class of which affects production of Wnt ligands. Breast cancer, in which excessive Wnt signalling appears to be driven by ligand rather than mutations in the $\beta$-catenin destruction complex, could be particularly responsive to treatment with such inhibitors, as well as with secreted inhibitors such as sFRPs, whose efficacy was illustrated in this study [1]. The advantage of inhibition at the level of the ligand would be to inhibit all $\beta$ catenin-dependent and -independent effects of Wnt signalling, including the PCP and PKC pathways.

The possibility that both $\beta$-catenin-dependent and -independent Wnt signalling contribute to tumourigenesis in breast cancer opens many new directions to study, and may provide valuable therapeutic insights.

\section{Competing interests}

The authors declare that they have no competing interests.

\section{References}

1. Matsuda Y, Schlange T, Oakeley EJ, Boulay A, Hynes NE: WNT signaling enhances breast cancer cell motility and blockade of the WNT pathway by SFRP1 suppresses MDA-MB-231 xenograft growth. Breast Cancer Res 2009, 11:R32.

2. Civenni G, Holbro T, Hynes NE: Wnt1 and Wnt5a induce cyclin D1 expression through ErbB1 transactivation in $\mathrm{HC} 11$ mammary epithelial cells. EMBO Rep 2003, 4:166-171.

3. Schlange $T$, Matsuda $Y$, Lienhard S, Huber A, Hynes NE:
Autocrine WNT signaling contributes to breast cancer cell proliferation via the canonical WNT pathway and EGFR transactivation. Breast Cancer Res 2007, 9:R63.

4. Nusse R, Varmus HE: Many tumors induced by the mouse mammary tumor virus contain a provirus integrated in the same region of the host genome. Cell 1982, 31:99-109.

5. Ayyanan A, Civenni G, Ciarloni L, Morel C, Mueller N, Lefort K, Mandinova A, Raffoul W, Fiche M, Dotto GP, Brisken C: Increased Wnt signaling triggers oncogenic conversion of human breast epithelial cells by a Notch-dependent mechanism. Proc Natl Acad Sci USA 2006, 103:3799-3804.

6. Polakis P: Wnt signaling and cancer. Genes Dev 2000, 14: 1837-1851.

7. Lin SY, Xia W, Wang JC, Kwong KY, Spohn B, Wen Y, Pestell RG, Hung MC: Beta-catenin, a novel prognostic marker for breast cancer: its roles in cyclin D1 expression and cancer progression. Proc Natl Acad Sci USA 2000, 97:4262-4266.

8. Milovanovic T, Planutis K, Nguyen A, Marsh JL, Lin F, Hope C, Holcombe RF: Expression of Wnt genes and frizzled 1 and 2 receptors in normal breast epithelium and infiltrating breast carcinoma. Int J Oncol 2004, 25:1337-1342.

9. Bafico A, Liu G, Goldin L, Harris V, Aaronson SA: An autocrine mechanism for constitutive Wnt pathway activation in human cancer cells. Cancer Cell 2004, 6:497-506.

10. Kohn AD, Moon RT: Wnt and calcium signaling: beta-cateninindependent pathways. Cell Calcium 2005, 38:439-446.

11. Weeraratna AT, Jiang $Y$, Hostetter G, Rosenblatt K, Duray $P$, Bittner M, Trent JM: Wnt5a signaling directly affects cell motility and invasion of metastatic melanoma. Cancer Cell 2002, 1: 279-288.

12. Teissedre $B$, Pinderhughes $A$, Incassati $A$, Hatsell SJ, Hiremath $M$, Cowin P: MMTV-Wnt1 and $\triangle \mathrm{N} 89 \beta$-catenin induce canonical signaling in distinct progenitors and differentially activate Hedgehog signaling within mammary tumors. PLoS One 2009, 4:e4537.

13. Collu GM, Brennan K: Cooperation between Wnt and Notch signalling in human breast cancer. Breast Cancer Res 2007, 9: 105.

14. Chen B, Dodge ME, Tang W, Lu J, Ma Z, Fan CW, Wei S, Hao W, Kilgore J, Williams NS, Roth MG, Amatruda JF, Chen C, Lum $\mathrm{L}$ : Small molecule-mediated disruption of Wnt-dependent signaling in tissue regeneration and cancer. Nat Chem Biol 2009, 5:100-107. 